\title{
Psychometric Properties of the Turkish Version of the 'Nine to Eleven-Year-Olds' Attitudes Towards Breakfast Questionnaire
}

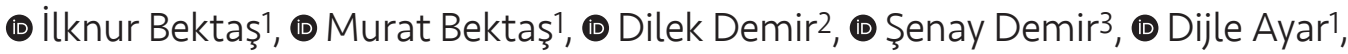 \\ (D) Aslı Akdeniz Kudubeş1 \\ 1Dokuz Eylül University Faculty of Nursing, İzmir, Turkey \\ 2Dokuz Eylül University Health Science Institute, Department of Pediatric Nursing, İzmir, Turkey \\ ${ }^{3}$ Selçuk University Vocational School of Health Services, Konya, Turkey
}

\begin{abstract}
Aim: This study has been carried out to evaluate the validity and reliability of the Turkish version of the ' 9 to 11-Year-Olds' Attitudes towards Breakfast Questionnaire.

Materials and Methods: This study was conducted with 646 children. Data were collected by a socio-demographic data form and the ' 9 to 11-Year-Olds' Attitudes towards Breakfast Questionnaire. Factor analysis, Cronbach's alpha, item-total correlation and contrasting group comparison were used in the evaluation of the data.

Results: The scale consists of 13 items and uni-dimensions which accounted for $32.45 \%$ of the total variance. All the factor loadings were found to be greater than 0.30 in both explanatory and confirmatory factor analysis. All of the fit indices were greater than 0.90 and root mean square error of approximation was less than 0.08. For the whole of the scale, Cronbach's alpha was found to be 0.82 .

Conclusion: The ' 9 to 11-Year-Olds' Attitudes towards Breakfast Questionnaire is a valid and reliable measurement tool for the Turkish sample. By using this scale, researchers can identify students' attitudes towards breakfast, reduce negative behaviors, and develop programs to improve positive attitudes in children towards breakfast.
\end{abstract}

Keywords: Children, breakfast, attitude, questionnaire

\section{Introduction}

Adequate and balanced nutrition is very important for children's healthy growth, development and protection from diseases (1-3). The timely and regular consumption of essential nutrients required for new tissue production during the growth process is a special issue for children's health. For this reason, it is recommended that all children should eat regularly and consume different nutrients in all meals of the day for healthy growth and development (1-2). Of all the meals of the day, breakfast has a special place since it is the first meal of the day after a long sleep. A large part of the vitamins, minerals, proteins, and energy that the body needs is taken at breakfast (4). In addition, breakfast also has an important role in meeting the energy required for rapid growth and development in children and increasing their brain development and cognitive capacity (5). School children spend a large part of the day at school, their 
physical activities increase, and their energy requirements go up due to their involvement in an active learning process $(4,5)$. In order to meet this energy need, meals should be consumed without exception. These benefits further increase the importance of breakfast, especially for school children. Regular breakfast habits play a significant and positive role in the academic achievement of school age children $(6,7)$. Studies have emphasized that breakfast habits have a positive effect on adaptation to school, peer relationships, motivation, and willing participation in activities as well as academic achievement $(6,7)$. Regular breakfast has also been shown to provide physiological benefits such as balancing blood glucose levels and also reducing the risk of obesity and high blood pressure (6-9). The omission or irregularity of breakfast affects the food consumed by children and causes them to acquire non-healthy eating habits (9-11). Children often eat fast food in environments such as school canteens as they cannot have breakfast at home due to reasons such as early schooling and late rising. In addition, children who attend schools with no breakfast program prefer fast food between their short breaks $(12,13)$. This situation leads to many health problems in children such as a rapid increase in obesity, malnutrition, very low or excessive weight, inadequate physical activity, and sleep disorders (14-16). For this reason, it is extremely important to determine the attitudes of children towards breakfast. Increased obesity in recent years, changes in the nutritional habits of children, and the consumption of high-calorie foods with inadequate nutrients have further increased the importance of research on the eating attitudes of children (12-16). When the existing scales in the field are examined, it can be seen that they do an overall evaluation of children's eating habits rather than a meal-based evaluation. In our country, there are studies on eating habits, Body Mass indexes, and the obesity prevalence of school age children, but there is no valid and reliable measurement tool which evaluates meal-based breakfast habits. In addition, the school-age period is a special age group due to the transition to the adolescent period. Positive behaviors gained at these ages are maintained for a long time and negative behaviors can be intervened in this age period. For this reason, with the intention of filling a gap in the literature, this study was conducted to test the psychometric properties of the Turkish version of a scale which assesses the breakfast attitudes of 9 to 11-year-old children developed in 2007 by Tapper et al. (17) .

\section{Materials and Methods}

\section{Research Design}

This descriptive, comparative, correlational, and methodological study was carried out to test the reliability and validity of the Turkish version of the ' 9 to 11-Year-Olds' Attitudes towards Breakfast Questionnaire (ATBQ-T) which aims to determine the breakfast attitudes of children.

\section{Study Time and Setting}

Data were collected from three schools selected by a simple random sampling method among the primary and secondary schools of the Ministry of Education located in the central and western Anatolian region of Turkey. The data collection procedure was administered to the students by the researchers in a separate class hour for each class (each lesson took 40 minutes). Parental consent for the children to participate in the study was obtained.

\section{Sampling and Sampling Characteristics}

When sampling size is to be determined in studies, statistics experts suggest that at least 10 subjects per item should be involved in the factor analysis. (18). To do the validity and reliability study of the ' 9 to 11-Year-Olds' ATBQ-T', which has a total of 13 items, the sampling size was calculated to be 130 participants ensuring "10 participants per item". According to the Turkish National Education System, children aged between 9 and 11 are $4^{\text {th }}, 5^{\text {th }}$, and $6^{\text {th }}$ graders in primary and secondary schools; therefore, the children in these grades were targeted to make up the sampling population. To determine the invariance of the questionnaire more clearly, 646 students from the $4^{\text {th }}, 5^{\text {th }}$, and $6^{\text {th }}$ grades were involved in the study.

\section{Inclusion and Exclusion Criteria}

Children between the ages of 9 and 11 years, who voluntarily agreed to participate and who had a written consent from their parents were included in the study.

\section{Data Collection Tools and Their Features}

The data collection tools employed in the study were a socio-demographic data collection form designed by the researchers and the ' 9 to $11-Y e a r-O l d s$ ' ATBQ-T' developed in 2008 by Tapper et al (17).

The Socio-demographic Data Collection Form: This form includes questions about the characteristics of the students (age, gender, grade, education status of the parents, family income status, whether having breakfast at home or not, and the content of breakfast (cheese, milk, eggs etc).

'9 to 11-Year-Olds' Attitudes towards Breakfast Questionnaire: This is a 5-point Likert-type measurement tool developed by Tapper et al. (17) in 2008 which consists of 13 items evaluating the breakfast attitudes of 9 to 11-year-old age group children. The questionnaire has a single factor structure and analyzes feelings, beliefs, and 
behaviors related to breakfast. There is no cut-off point of the scale. High scores above the average of 13 items indicate more positive attitudes towards breakfast and lower scores show a negative attitude. The $1^{\text {st }}, 12^{\text {th }}$ and $13^{\text {th }}$ items of the scale are reverse scored. As a result of the analyses, it was found that it accounted for $32.74 \%$ of the variance with its single factor structure. Factor loads ranged from 0.38 to 0.69. The Cronbach's alpha coefficient was 0.82 .

\section{Study Steps}

Validity Analyses: Content and scope validity were used for the validity analyses.

Translation of the Scale: The scale was separately translated from English to Turkish by three linguists. Following this, the Turkish form of the scale was collaboratively formed by the researchers. The Turkish questionnaire was back-translated into English by a different English linguist (18-20).

Content Validity: Nine experts were referred to for an evaluation of the scale translated into Turkish in this study. They were asked to rate the translated version using scores ranging between 1 and 4 points. The items were revised taking their recommendations into consideration. The itembasis scope validity index (I-CVI) and the scale-basis scope Validity index (S-CVI) were calculated. In this analysis, 0.80 and above indicates agreement among experts. (18-22).

Pilot Study: To study a scale in terms of the language and comprehension of its statements, the scale should be applied to 20-30 people from a similar population (18-22). Following the translation studies, the scale was piloted to 20 individuals who were not involved in the real sampling but who had similar characteristics to subjects of the sampling.

Reliability of the Scale: The Cronbach's alpha, itemtotal and item-sub-scale score, floor/ceiling effects were used. Cronbach's alpha is desired to be above 0.70 (18-22). Item-total correlation is to be at least 0.20 . The floor and ceiling effects are required to be below 15\% (21).

Construct Validity: The construct validity was evaluated with exploratory factor analysis (EFA) and confirmatory factor analysis (CFA). The Kaiser-Meyer-Olkin (KMO) coefficient and Bartlett Sphericity test were calculated for EFA. To perform EFA, it is recommended that the KMO value be greater than 0.60 and the Barlett Sphericity test be $p<0.05$. In determining the factors, an eigenvalue was accepted to be 1 or higher. Statisticians emphasize that the factor value should be taken as 0.30. In the CFA, degree of freedom, Pearson chi-square, Goodness of Fit index
(GFI), root-mean-square error of approximation (RMSEA), Comparative Fit index (CFI) and normal fit index (NFI) were analyzed as fit indexes. It is recommended that RMSEA should be below $0.080, \mathrm{df} / \chi^{2}$ should be less than five, and the other indexes should be higher than 0.90 (23).

\section{Statistical Analysis}

The descriptive data were analyzed using number, percentages and means. The validity of the scale was analyzed using EFA and CFA. The reliability of the scale was evaluated by Cronbach's alpha coefficient and split-half analysis. The item-total score relationship was analyzed with Pearson correlation. T-test was used for contrast group comparison. Statistical significance was accepted as $\mathrm{p}<0.05$.

\section{Research Ethics}

Written consent from the Non-Invasive Clinical Studies Board of University (IRB: 2018/28-07), Directorate for National Education and from the parents of the children involved were received, and verbal permission was received from the children.

\section{Results}

$48.6 \%$ of the children $(n=309)$ who participated in the study were female, and the mean age was $10.24+1.20$ years (aged between 8 and 13). 53.0\% ( $n=337)$ were $4^{\text {th }}$ graders, $22.6 \%(n=144)$ were 5 th graders, and $24.4 \%(n=155)$ were $6^{\text {th }}$ graders. $43.4 \%(n=276)$ of the mothers were primary school graduates and $38.7 \%(n=246)$ of the fathers were primary school graduates. $26.6 \%$ of the children $(n=169)$ had two siblings. While $86.9 \%$ of the children reported that they had breakfast on a regular basis, $13.1 \%$ stated that they did not have breakfast. Of the children who had breakfast, 81.5\% $(n=451)$ had breakfast at home and the rest had breakfast at school.

The fit between the opinions of the experts included in the study was found to be between $0.95-1.00$ on item basis and 0.99 on a scale basis.

As a result of the EFA, KMO was found to be 0.855 , the Bartlett test $\chi^{2}$ value was 1954.896, and $p<0.01$. According to EFA, it was determined that the scale consists of one dimension. The scale accounted for $32.45 \%$ of the total variance. Factor loads ranged between 0.37 and 0.68 (Table I).

According to CFA, fit indexes were found to be follows: $\chi^{2}=185.970 ; \mathrm{df}=62, \chi^{2} / \mathrm{df}=2.99 ; \mathrm{RMSEA}=0.056 ; \mathrm{GFI}=0.96$; $\mathrm{CFI}=0.94$; incremental fit index $=0.94 ; \mathrm{NFI}=0.91$; Trucker Lewis index $=0.92$; Relatve Fix index $=0.88$. The factor loads 
were found to range from 0.30 to 0.66 as shown by CFA (Table II, Figure 1).

The mean scale scores of those children who had breakfast in the morning was $52.57+9.11$, whereas the mean scale score of those children who did not have breakfast was 43.27+11.69. The difference between the children's scores according to the status of having breakfast was significant ( $p<0.001$, Table III).

Cronbach's alpha coefficient was found to be 0.82 . According to analysis of split-half, the Cronbach's alpha values of the two halves were determined to be 0.72 and 0.70 , respectively. The Spearmen-Brown, Guttman half and correlation between the two halves were found to be 0.78 , 0.78 and 0.65 , respectively. The floor/ceiling effects were found to be $0.0 \%$ and $7.1 \%$, respectively (Table IV).

Hotelling's T2 test was conducted to examine the response bias. Hotelling's T2 was determined to be 481.459 and $p<0.01$. It was determined that there was no response bias on the scale.

The item-total correlation ranged between 0.37-0.66 (Table V).

Table I. Factor loadings for the one extracted factor after varimax rotation $(n=636)$

\begin{tabular}{|c|c|c|c|}
\hline Items & Factor loadings & Explained variance \% & Eigen value \\
\hline 1 & 0.37 & \multirow{8}{*}{32.45} & \multirow{8}{*}{4.219} \\
\hline 2 & 0.68 & & \\
\hline 3 & 0.61 & & \\
\hline 4 & 0.63 & & \\
\hline 5 & 0.65 & & \\
\hline 6 & 0.58 & & \\
\hline 7 & 0.46 & & \\
\hline 8 & 0.53 & & \\
\hline 9 & 0.57 & & \\
\hline 10 & 0.67 & & \\
\hline 11 & 0.34 & & \\
\hline 12 & 0.36 & & \\
\hline 13 & 0.54 & & \\
\hline
\end{tabular}

\section{Discussion}

In this study, it was found that the I-CVI and S-CVI were above 0.80 regarding the analysis of the fit between the experts, harmony between experts' opinions was found, and that the items represented the desired area sufficiently (1823). These results supported the CVI of the scale.

$\mathrm{KMO}$ and Bartlett's $\chi^{2}$ tests were employed to determine whether the sampling of the study was suitable for EFA. When Bartlett's test is significant, it indicates that the data are suitable for EFA and when $\mathrm{KMO}$ is greater than 0.60 , it indicates that the sampling size is adequate for EFA. In this

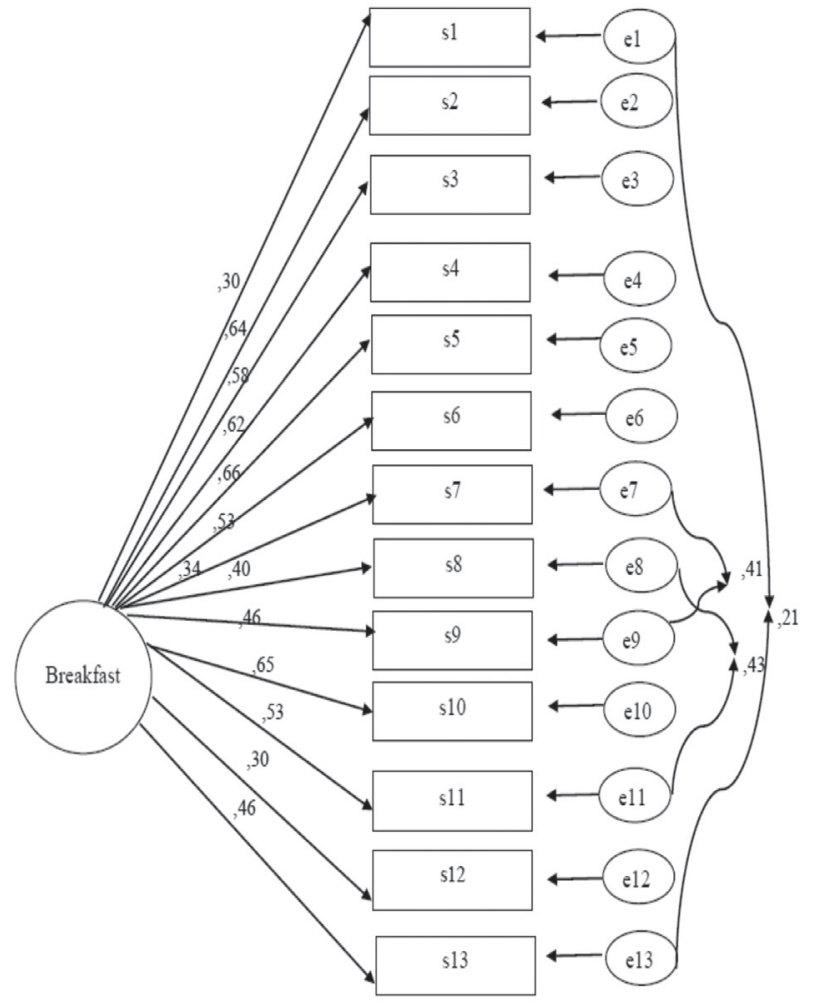

Figure 1. The Breakfast Attitudes Questionnaire

Table III. Comparison of mean scale scores according to the status of having breakfast (known group comparison $(n=636)$

\begin{tabular}{|l|l|l|l|l|}
\cline { 1 - 3 } Has breakfast & $\mathbf{n}$ & $\mathbf{M}+$ SD & t & $\mathbf{p}$ \\
\cline { 1 - 3 } Yes & 553 & $52.57+9.11$ & \multirow{2}{*}{6.933} & \multirow{2}{*}{0.000} \\
\cline { 1 - 3 } No & 83 & $43.27+11.69$ & & \\
\hline \multicolumn{7}{|l|}{ M: Mean, SD: Standard deviation, n: Number } \\
\hline
\end{tabular}

Table II. Model fit indices of the breakfast attitudes questionnaire

One factor model

\begin{tabular}{|l|l|l|l}
$\mathbf{X}^{\mathbf{2}}$ & DF $^{\mathbf{a}}$ & $\mathbf{X}^{\mathbf{2}} / \mathbf{D F}$ & RMSEA $^{\mathbf{b}}$ \\
\hline 185.970 & 62 & 2.99 & 0.056
\end{tabular}

\begin{tabular}{|l|l|l|l|l|l} 
GFI $^{\mathbf{c}}$ & CFI $^{\mathbf{d}}$ & $\mathbf{I F I}^{\mathbf{e}}$ & $\mathbf{R F I}^{\mathbf{f}}$ & $\mathbf{N F I}^{\mathbf{g}}$ & $\mathbf{T L I}^{\mathbf{h}}$ \\
\hline 0.96 & 0.94 & 0.94 & 0.88 & 0.91 & 0.92
\end{tabular}

a: Degree of freedom, b: Root mean square error of approximation, c: Goodness of fit index, d: Comparative fit index, e: Incremental fit index, f: Relative fit index, $\mathrm{g}$ : Normed fit index, TLI:Trucker-Lewis index 
study, Bartlett's chi-square test was found to be significant and the KMO value was determined to be greater than 0.60 , which indicated that the data in this study were suitable for factor analysis and the sample size was adequate (18-23).

It is emphasized in the literature that a variance of $30 \%$ or above explained in unidimensional scales is satisfactory (18-22). According to EFA, it was found that the scale was composed of one dimension and this one-dimensional scale accounted for $32.45 \%$ of the total variance. The original scale also consists of one dimension and it accounted for $32.74 \%$ of the total variance (17). The total variance calculated in this study was similar to the total variance calculated in the original scale (17). This finding showed that the construct of the Turkish version of the scale was similar to the original one. In this study, the factor loadings of the scale were found to range between 0.37-0.68. The factor loadings of the original scale range between 0.38-0.69 (17). In the field, it is emphasized that the factor load should be at least 0.30 (18-22). In this study, since the factor loadings of all the items in the scale were greater than 0.30 and they were similar to the ones in the original scale, the Turkish version could be said to maintain the original construct and have a good factor construct for Turkish sampling. The results of this study show that the Turkish form had good construct validity.

It is also emphasized in the literature that a CFA should be conducted in the examination of construct validity, especially if a cultural adaptation is being performed (1823). The conformity of factor construct determined by EFA in this study was also evaluated by CFA. As a result of the CFA, it was found that the $\mathrm{df} / \chi^{2}$ was less than 5 , RMSEA was below 0.08 , the indices were higher than 0.90 , and that the factor loads were higher than 0.30. As CFA findings were not presented in the original study (17), these study results could not be compared to those of the original scale. The fact that the fit indexes in the CFA used to determine the harmony of the construct determined by EFA to real life is above 0.90 in the literature, the RMSEA is below $0.08, \mathrm{df} / \chi^{2}$ is less than 5 , and that the factor loads are greater than 0.30 indicates that the scale confirmed its factor construct. The CFA results reveal that the CFA confirmed the single-factor construct, the items identified their own factor sufficiently and measured the target concept adequately (18-23).

Another method used to determine construct validity is contrast group comparison. In this method, group means, which are likely to get different scores from the scale, are compared, and thus a difference is expected (18-23). In this study, the scale scores of those students who had breakfast and those who did not have breakfast were used to compare to the known group. In this study, the scores of those children who had breakfast were found to be significantly higher than those who did not have breakfast $(p<0.01)$. These results reveal that the scale could distinguish between the groups that were expected to be different in terms of the characteristics that the scale intended to measure, which revealed that the scale had good construct validity. In the original study, it was determined that children who often skipped breakfast had more negative attitudes towards breakfast than those who skipped breakfast less frequently (17). These results were in line with those of the original scale.

Table V. Correlations of the item total score and sub-scale total score $(n=636)$

\begin{tabular}{|l|l|}
\hline Items & Item-total score correlation* \\
\hline 1. & 0.37 \\
\hline 2 & 0.66 \\
\hline 3 & 0.61 \\
\hline 4 & 0.60 \\
\hline 5 & 0.61 \\
\hline 6 & 0.56 \\
\hline 7 & 0.51 \\
\hline 8 & 0.55 \\
\hline 9 & 0.61 \\
\hline 10 & 0.63 \\
\hline 11 & .063 \\
\hline 12 & 0.42 \\
\hline 13 & 0.53 \\
\hline$* \mathrm{p}<0.001$ & \\
\hline
\end{tabular}

Table IV. The results for the reliability analysis of the scale $(n=636)$

\begin{tabular}{|l|l|l|l|l|l|l|l|l|l|}
\hline Sub-scales & $\begin{array}{l}\text { Cronbach } \\
\alpha\end{array}$ & $\begin{array}{l}\text { First half } \\
\text { cronbach } \\
\alpha\end{array}$ & $\begin{array}{l}\text { Second half } \\
\text { cronbach } \\
\alpha\end{array}$ & $\begin{array}{l}\text { Spearman- } \\
\text { brown }\end{array}$ & $\begin{array}{l}\text { Guttman } \\
\text { split-half }\end{array}$ & $\begin{array}{l}\text { Correlation } \\
\text { between } \\
\text { the two } \\
\text { halves }\end{array}$ & $\begin{array}{l}\text { M } \pm \text { SD } \\
\text { (Min-Max) }\end{array}$ & $\begin{array}{l}\text { Floor } \\
\text { effect } \\
\%\end{array}$ & $\begin{array}{l}\text { Ceiling } \\
\text { effect } \\
\%\end{array}$ \\
\hline Scale totals & 0.82 & 0.72 & 0.70 & 0.78 & 0.78 & 0.65 & $51.36 \pm 9.98(21-65)$ & 0.0 & 7.1 \\
\hline
\end{tabular}


Cronbach's alpha is the most commonly recommended method to be used in determining reliability. In scales, it is desired that the Cronbach's alpha value is above 0.70 (18-22). In this study, the Cronbach's alpha coefficient of the scale was 0.82 . The reliability coefficient of this study was over 0.80, which showed high reliability. In addition, the alpha value of the original scale was also 0.82 (17), therefore, the alpha values of the two studies were in line with each other. In the literature, another of the methods recommended to be used for reliability is the split-half. In this analysis, it is recommended that the alpha values of the two halves, the Spearman-Brown and Guttman split-half should be above 0.70 (18-22). In this study, it was found that the Cronbach's alpha of both halves, the Spearman-Brown and Guttman split-half were above 0.70 and there was a high relationship between the two halves. These results showed that each item was highly correlated with the scale, they determine that the topic is measured adequately, the scale measures the attitudes of the children towards breakfast satisfactorily, and that the reliability of the scale is high.

One of the critical factors affecting scales is response bias. Response bias occurs when the respondents do not base their answers on their own opinions but give responses in accordance with the society's or the researchers' expectations (18-22). In this study, the existence of response bias was analyzed by Hotelling's T2 analysis and it was determined that there was no response bias in the scale. This finding supported the conclusion that the scale had both reliability and validity.

In the literature, it is recommended that the floor/ ceiling effect be evaluated in scales, and that the floor/ ceiling effect should be below 20\% (18-23). In this study, the floor/ceiling effect was found to be below $20 \%$. The low floor/ceiling effect values in the study showed that the scale was reliable and it adequately measured the required construct to be measured (18-23).

It is recommended to perform item-total score analysis in psychometric studies. It shows the extent to which the items in the scale are correlated to the scale and whether it measures the desired feature (18-22). The correlation coefficient was calculated in this analysis. This value is expected to be positive and greater than 0.20 (18). In this study, item-total score correlation was found to be positive and greater than 0.20 . In this study, it was determined that all items of the scale had a high level of correlation with the total score, that they measured the required qualification to a sufficient level and that the scale items had a high level of reliability.

\section{Study Limitation}

The limitation of this study was the use of a convenience sampling method. This may have affected the generalizability of the study.

\section{Conclusion}

In conclusion, it was determined that the Turkish scale has good validity and reliability. By using this scale, researchers can identify students' attitudes towards breakfast, reduce negative behaviors, and develop programs to improve positive attitudes in children towards breakfast. They can also carry out cross-cultural comparative studies using this scale.

\section{Ethics}

Ethics Committee Approval: Written consent from the non-invasive Clinical Studies Board of University (IRB: 2018/28-07), Directorate for National Education and from the parents of the children involved were received, and verbal permission was received from the children.

Informed Consent: Written consent from parents.

Peer-review: Enternally peer-reviewed.

\section{Authorship Contributions}

Surgical and Medical Practices: I.B., D.D., Ş.D., D.A., A.A.K., Concept: I.B., D.D., Ş.D., D.A., A.A.K., Data Collection or Processing: M.B., D.D., ş.D., D.A., A.A.K., Analysis or Interpretation: M.B., Literature Search: M.B., Writing: I.B.

Conflict of Interest: None of the authors had conflict of interest.

Financial Disclosure: The authors declared that this study received no financial support.

\section{References}

1. Afshin A, Micha R, Khatibzadeh S, et al. The impact of dietary habits and metabolic risk factors on cardiovascular and diabetes mortality in countries of the Middle East and North Africa in 2010: a comparative risk assessment analysis. BMJ Open 2015; 5:e006385.

2. Micha R, Peñalvo $\mathrm{L}$, Cudhea $F$, et al. Association between dietary factors and mortality from heart disease, stroke, and type 2 diabetes in the United States. IAMA 2017; 317:912-24.

3. Deshmukh-Taskar P, Nicklas TA, Radcliffe JD, O'Neil CE, Liu Y. The relationship of breakfast skipping and type of breakfast consumed with overweight/obesity, abdominal obesity, other cardiometabolic risk factors and the metabolic syndrome in young adults. The National Health and Nutrition Examination Survey (NHANES): 1999-2006. Public health nutrition 2013; 16:2073-82.

4. Coulthard JD, Palla L and Pot GK. Breakfast consumption and nutrient intakes in 4-18-year-olds: UK National Diet and 
Nutrition Survey Rolling Programme (2008-2012). British Journal of Nutrition 2017; 118:280-290.

5. Maclnerney EK, Swatzyna RJ, Roark AJ, et al. Breakfast choices influence brainwave activity: Single case study of a 12-year-old female. International Society of Neurofeedback and Research 2017; 4:56-62.

6. Edefonti $V$, Rosato $V$, Parpinel $M$, et al. The effect of breakfast composition and energy contribution on cognitive and academic performance: a systematic review. The American journal of clinical nutrition 2014; 100:626-56.

7. Ho CY, Huang YC, Lo YTC, Wahlqvist M, Lee MS. Breakfast is associated with the metabolic syndrome and school performance among Taiwanese children. Research in developmental disabilities 2015; 43:179-188.

8. Ptomey LT, Steger FL, Schubert MM, et al. Breakfast intake and composition is associated with superior academic achievement in elementary schoolchildren. Journal of the American College of Nutrition 2016; 35:326-33.

9. Littlecott HI, Moore GF, Moore L, Lyons RA, Murphy S. Association between breakfast consumption and educational outcomes in 9-11-year-old children. Public health nutrition $2016 ; 19: 1575-82$

10. Nurul-Fadhilah A, Teo PS, Huybrechts I, Foo LH. Infrequent breakfast consumption is associated with higher body adiposity and abdominal obesity in Malaysian school-aged adolescents. PloS one 2013; 8:e59297.

11. Sampasa-Kanyinga $\mathrm{H}$, Hamilton $\mathrm{HA}$. Eating breakfast regularly is related to higher school connectedness and academic performance in Canadian middle-and high-school students. Public health 2017; 145:120-3.

12. Tee ES, Nurliyana AR, Norimah AK, et al. Breakfast consumption among Malaysian primary and secondary school children and relationship with body weight status-Findings from the My Breakfast Study. Asia Pacific journal of clinical nutrition 2018; 27:421-32.

13. Orhan A, Çelik i. Ilköğretim okulu öğrencilerinin kahvaltı alışkanlıkları ve okul kantini ile ilişkilerinin belirlenmesi Akademik Gıda 2014; 12:51-6.
14. Smith KJ, Breslin MC, McNaughton SA, Gall SL, Blizzard L, Venn AJ. Skipping breakfast among Australian children and adolescents; findings from the 2011-12 National Nutrition and Physical Activity Survey. Australian and New Zealand journal of public health 2017; 41:572-8.

15. Blondin SA, Anzman-Frasca S, Djang HC, Economos CD. Breakfast consumption and adiposity among children and adolescents: an updated review of the literature. Pediatric obesity 2016; 11:333-348.

16. Savaşhan Ç, Erdal M, Sarı O, et al. illkokul çağındaki çocuklarda obezite görülme sıklığı ve risk faktörleri. Türkiye Aile Hekimliği Dergisi 2015; 19:14-21.

17. Tapper K, Murphy S, Lynch R, et al. Development of a scale to measure 9-11-year-olds' attitudes towards breakfast. European journal of clinical nutrition 2008; 62:511.

18. Şencan $H$. Sosyal ve davranışsal ölçümlerde güvenilirlik ve geçerlilik (reliability and validity in social and behavioral measurement). 1.edition, Ankara: Seçkin Yayınevi 2005.

19. Polit DF, Beck CT and Owen SV. Is the CVI an acceptable indicator of content validity? Appraisal and recommendations. Res Nurs Health 2007; 30:459-67.

20. Rattray I and Jones MC Essential elements of questionnaire design and development. Journal of Clinical Nursing 2007;16:23443.

21. Terwee $C B$, Bot $S D$, de Boer $M R$, et al. Quality criteria were proposed for measurement properties of health status questionnaires. J Clin Epidemiol 2007; 60:34-42.

22. DeVellis RF. Scale development, theory and Applications. 3rd ed. India, SACE Publication Inc 2012:31-59.

23. Şimşek ÖF. Yapısal Eşitlik modellemesine giriş temel ilkeler ve LISREL Uygulamaları (Introduction to Structural Equation Modeling, LISREL Fundamental Principles and Practices). İstanbul: Ekinoks; 2010. 